\title{
Home-Based Cardiac Rehabilitation (HBCR) In Post- TAVR Patients: A Prospective, Single-Center, Cohort, Pilot Study
}

\author{
Gurjaspreet K. Bhattal (D) - Ki E. Park - David E. Winchester
}

Received: May 11, 2020 / Published online: June 13, 2020

(C) The Author(s) 2020
Digital features: To view digital features for this article go to https://doi.org/10.6084/m9.figshare.12416336.

G. K. Bhattal $(\varangle)$ - K. E. Park · D. E. Winchester University of Florida Health, Gainesville, FL, USA e-mail: gurjaspreet.bhattal@medicine.ufl.edu; gurjaspreet.kaur@gmail.com

K. E. Park · D. E. Winchester

Malcom Randall Department of Veterans Affairs

Medical Center, North Florida South Georgia

VAMC, Gainesville, FL, USA completed the surveys. We used various performance measures including Life's Simple 7 survey, 6-min Walk (6-MW), Duke Activity Survey Index (DASI), and Short Form-36 (SF-36) health survey to assess the pre and post-HBCR changes in emotional, functional, and physical well-being of the patients.

Results: Paired comparison of pre and postHBCR using Wilcoxon signed-rank test revealed a statistically significant difference in the pre and post-HBCR scores for DASI, DASI-Mets, and SF-36 physical functioning ( $p$ values $0.05,0.034$, and 0.016, respectively), suggesting an improvement in the patients' physical functioning after participating in the HBCR program.

Conclusions: In conclusion, our pilot study offers novel insight into the role of HBCR in improving physical health and well-being in post-TAVR patients while eliminating the barriers of transportation and access to cardiac rehabilitation programs.

Keywords: Aortic valve replacement; Cardiac rehabilitation; Home-based cardiac rehabilitation; TAVR 


\section{Key Summary Points}

Why carry out this study?

Cardiac rehabilitation after TAVR has been well reported to safely improve exercise tolerance, functional independence, and quality of life. However, barriers such as lack of transportation and limited access to rehabilitation programs limit participation.

To mitigate these barriers, the Veterans Affairs Medical System (VAMC) started a 12-week-long home-based cardiac rehab (HBCR) program in 2010.

To investigate the benefit of HBCR, we assessed the functional status of 14 patients upon completion of HBCR after TAVR between 2015 and 2018 at NFSG VAMC.

\section{What was learned from this study?}

Paired comparisons revealed a significant difference in pre- and post-HBCR scores for DASI (Duke Activity Status Index), DASI-Mets, and SF-36 physical functioning scores ( $p$ values $0.05,0.034$, and 0.016 , respectively).

This pilot study highlights the benefit of home-based cardiac rehabilitation in improving physical functioning while eliminating the barriers of access to facility-based cardiac rehabilitation.

\section{INTRODUCTION}

Transcatheter aortic valve replacement (TAVR) is recommended in both intermediate- and high-risk patients with severe symptomatic or asymptomatic aortic stenosis [1]. Since its approval in 2011, more than 260,000 TAVRs have been performed on patients who are at high risk for surgical AVRs. As such, the role of cardiac rehabilitation in restoring functional capacity after TAVR has been widely studied. Several studies have shown an improvement in exercise tolerance, functional independence, and quality of life in post-TAVR patients who participated in cardiac rehabilitation [2-6]. However, lack of transportation and limited access to rehabilitation programs prohibit participation in cardiac rehab [7]. To increase participation by reducing such barriers, the Veterans Affairs Medical Center (VAMC) started a 12-week-long, physician-supervised, nursemanaged, home-based cardiac rehab (HBCR) program in 2010 for patients with a broad range of cardiovascular disease conditions. In our prospective, single-center, one-arm study, we sought to assess the functional status of 14 patients who completed HBCR after TAVR between 2015 and 2018 through the Gainesville VAMC, a major referral center for TAVRs in the VA system.

\section{METHODS}

Fifty-nine patients who underwent TAVR at NFSG VAMC from 2015 to 2018 were offered the HBCR program the time of discharge. Fortyone enrolled, 28 completed the program, and 14 of those completed the surveys (Table 1). Of the patients who participated in the program, two were females. The geographical locations of participants are shown in Fig. 1. No other baseline characteristics or lab values were collected as a part of this pilot study.

Inclusion criteria for enrollment in HBCR included age greater than 18 years, TAVR within 12 months, and ability to read, write, and fillout questionnaires. Exclusion criteria were inability to attend daily exercise, complex ventricular arrhythmias, resting systolic blood pressure greater than $200 \mathrm{mmHg}$ and diastolic blood pressure greater than $100 \mathrm{mmHg}$, decompensated congestive heart failure, history of arrhythmia with syncope, severe symptomatic untreated valvular disease, unstable angina, dementia, or other higher cognitive impairment limiting participation, and life expectancy of less than 1 year.

All eligible patients were referred for HBCR at time of discharge and the program lasted for 
Table 1 Patient characteristics for the post-TAVR home-based cardiac rehabilitation (HBCR) program

Patients offered HBCR

Number enrolled

Number that declined the HBCR program

Number that completed the HBCR program

Number of males

\section{9}

$41(69 \%$ of total)

18 (31\% of offered)

28 (68\% of enrolled)

26 (92\% of those who completed the program)

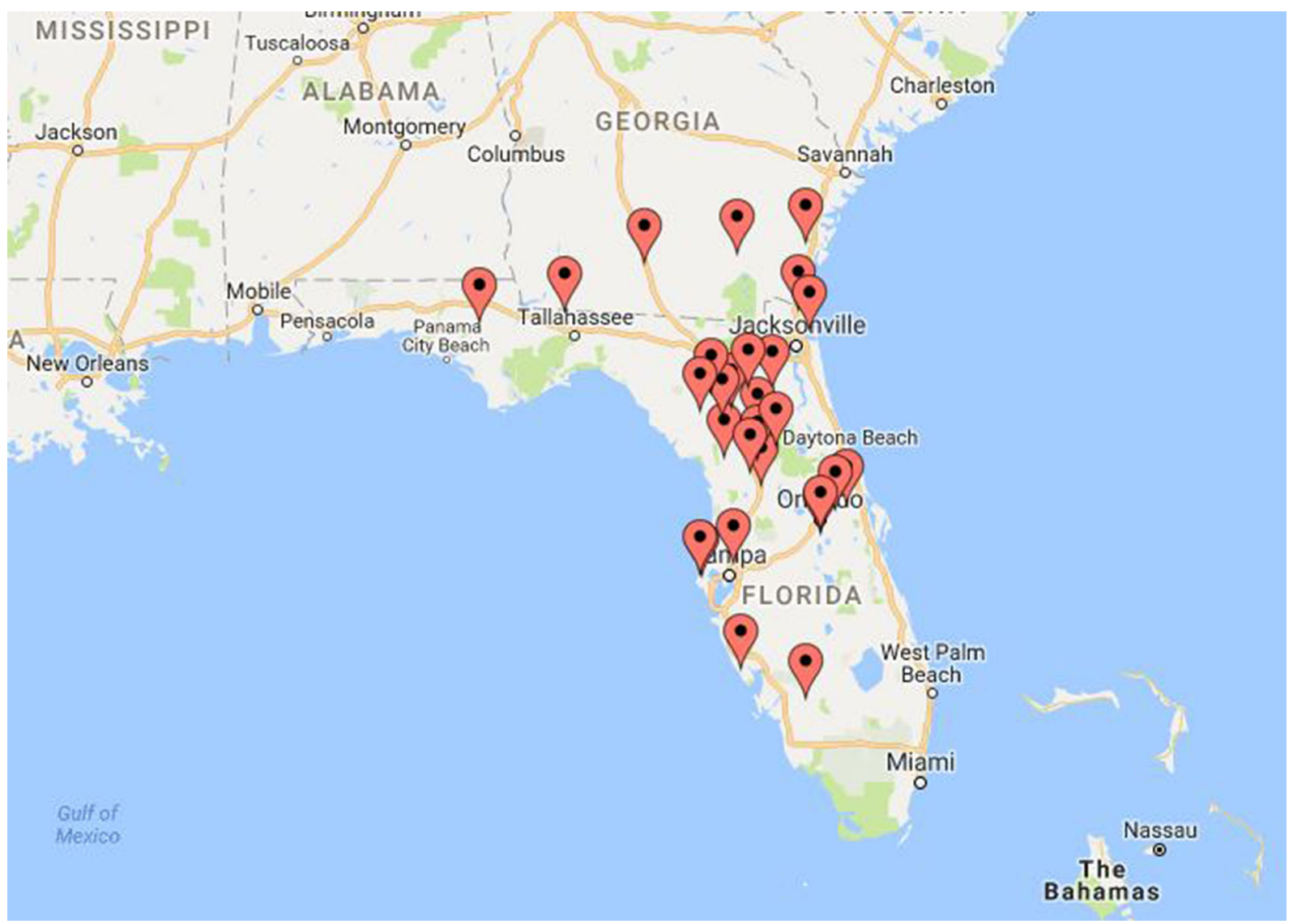

Fig. 1 Geographical distribution of patients who completed the home-based cardiac rehab (HBCR) program after TAVR at Malcom Randall VAMC

12 weeks. Participants filled out a baseline assessment questionnaire prior to participation indicating their functional capacity.
Individualized plans including strength, aerobic, and balance exercises were then created for each participant based on their capacity and 
goals. A basic beginner's exercise plan is shown below:

\begin{tabular}{ll}
\hline Exercise prescription & Resistance exercise \\
\hline Mode & Resistance/weight \\
$\begin{array}{l}\text { Aerobic/walking/ } \\
\text { peddling }\end{array}$ & Stretching/TheraBands \\
Frequency: 3 days per & Repetitions: $3-5$ min or 5-10 \\
week & reps \\
Duration: 5 min & Progression: as tolerated \\
Intensity: light & \\
Progression: as tolerated & \\
\hline
\end{tabular}

Equipment such as resistance bands, peddler, pedometer, BP cuff, and scale were provided for use at home. A pedometer was used to track steps while walking; a stationary peddler was used for upper or lower extremity exercise; and resistance bands were used for strengthening exercises. Through weekly telephone supervision from a nurse, participants performed up to $2 \mathrm{~h}$ of physical exercise at home per day. Education about a healthy diet, food preparation, and logging intake of food was also provided. Furthermore, counseling on smoking cessation, stress management, and psychosocial consultation was also provided via weekly telephone calls.

Various performance measures including Life's Simple 7 survey, 6-min Walk (6-MW), Duke Activity Survey Index (DASI), and Short Form-36 (SF-36) health survey were used to assess the pre- and post-HBCR changes in emotional, functional, and physical well-being of the patients.

- The Life's Simple 7 survey is a health metric that includes seven components and 18 questions about smoking status, physical activity, healthy diet score, body mass index, blood pressure, total cholesterol, and blood fasting glucose [8]. The scoring range for this test is $0-14$. Each category receives a score of
0,1 , or 2 for quality of health -0 being poor, 1 being intermediate, and 2 being ideal.

- 6-MW test was used to measure the patient's submaximal exercise capacity by measuring the distance a patient can quickly walk on a flat, hard surface in a period of $6 \min$ [9]. The outcome is measured in feet.

- DASI is a 12-item questionnaire used to measure functional capacity such as personal care, ambulation, household tasks, sexual function, and recreation [10]. Each item in this questionnaire is weight-based and the "yes" responses add up to make the final score. The higher the score, the better the functional status. Scores range between zero and 58.2. The DASI-Mets range is between zero and 9.89 .

- The SF-36 is a patient self-reported questionnaire to evaluate eight domains including patients' physical functioning (PF), physical role limitation due to physical health (RP), and physical role limitation due to emotional problems (RE), social functioning (SF), bodily pain (BP), mental health $(\mathrm{MH})$, vitality (VT), and general health (GH). Scoring of each domain is calculated independently and scores range from 0 to 100; the lower the score the greater the disability [11].

SPSS version 22 was used for data analysis. Wilcoxon signed-rank test was used to generate paired comparisons. A $P$ value $\leq 0.05$ was considered significant. Resources and facilities were provided by the Malcom Randall Veterans Affairs Medical Center. In accordance with Veterans Affairs Handbook 1058.05, this quality improvement project was determined to not qualify as human subjects' research. As such, this project was not reviewed by our institutional review.

\section{RESULTS}

After 12 weeks of HBCR, 14 out of the 28 who participated in the program completed all the questionnaires. Paired comparisons using the Wilcoxon signed-rank test are listed in Table 2.

Notable findings include: 
Table 2 Paired pre- and post-HBCR comparisons of physical and emotional functionality in TAVR patients

\begin{tabular}{|c|c|c|c|c|c|c|}
\hline \multirow[t]{2}{*}{ Instrument } & \multirow[t]{2}{*}{ Scoring } & \multicolumn{4}{|c|}{$\begin{array}{l}\text { Median scores and interquartile range (IQR) } \\
(n=14)\end{array}$} & \multirow[t]{2}{*}{$\begin{array}{l}\text { Wilcoxon signed- } \\
\text { rank test } p \text { values* }\end{array}$} \\
\hline & & $\begin{array}{l}\text { Pre-HBCR } \\
\text { median }\end{array}$ & $\begin{array}{l}\text { Pre- } \\
\text { HBCR } \\
\text { IQR }\end{array}$ & $\begin{array}{l}\text { Post- } \\
\text { HBCR } \\
\text { median }\end{array}$ & $\begin{array}{l}\text { Post- } \\
\text { HBCR } \\
\text { IQR }\end{array}$ & \\
\hline Simple-7 & $0-10$ & 6.0 & 1.8 & 7.0 & 2.5 & 0.281 \\
\hline DASI & $0-58.2$ & 14.3 & 22.2 & 24.2 & 17.4 & 0.050 \\
\hline DASI-Mets & $0-9.89$ & 4.5 & 2.7 & 5.7 & 2.1 & 0.034 \\
\hline SF-36 & $0-100$ per domain & & & & & \\
\hline \multicolumn{7}{|c|}{ SF-36 domains } \\
\hline PF & (Physical functioning) & 30 & 42.5 & 62.5 & 28.8 & 0.016 \\
\hline $\mathrm{RP}$ & $\begin{array}{l}\text { (Physical role limitation due to } \\
\text { physical health) }\end{array}$ & 0 & 0 & 0 & 43.8 & 0.107 \\
\hline $\mathrm{BP}$ & (Bodily pain) & 51.5 & 34.4 & 57.5 & 22.5 & 0.314 \\
\hline $\mathrm{GH}$ & (General health) & 40.0 & 44.7 & 51.1 & 23.8 & 0.727 \\
\hline VT & (Vitality) & 42.5 & 28.8 & 50 & 22.5 & 0.309 \\
\hline SF & (Social functioning) & 75 & 43.8 & 93.7 & 46.9 & 0.282 \\
\hline $\mathrm{RE}$ & $\begin{array}{l}\text { (Physical role limitation due to } \\
\text { emotional problems) }\end{array}$ & 49.8 & 100 & 100 & 33.3 & 0.094 \\
\hline MH & (Mental health) & 76 & 34 & 80 & 26 & 0.888 \\
\hline
\end{tabular}

HBCR - home-based cardiac rehabilitation, $T A V R$ - transcatheter aortic valve replacement, $6-M W$ - 6-min Walk test, $D A S I$ - Duke Activity Status Index, $S F-36$ - Short-Form Health Survey $-36,{ }^{*} p$ value $\leq 0.05$ considered significant (bolded values in the table)

- Life's Simple 7 survey revealed no significant change.

- The median score for pre-HBCR DASI survey was 14.3 while the post-HBCR median score was 24.2 with a $p$ value of 0.050 . Additionally, DASI-Mets score before was HBCR was 4.5, which improved to 5.7 (maximum score 9.89) with a $p$ value of 0.034 .

- Among the subcategories of SF-36, statistically significant improvement was noted in the physical functioning domain with median score increasing to 62.5 after HBCR from 30 before ( $p$ value of 0.016 ).

- While not statistically significant, an absolute increase in score from 49.8 to 100 was noted in the physical role limitation due to emotional problems (RE) domain of SF-36 indicating an overall improvement in this category post-rehabilitation.

- The statistical analysis for physical role limitation due to physical health (RP) was not valid because this survey category was not consistently filled out by participants before and after HBCR.

- The bodily pain (BP) domain noted a slight increase in post-HBCR median score from 51.5 to 57.5 .

- A Wilcoxon paired test was not performed for the $6 \mathrm{MW}$ test since only five of 14 patients completed the clinic visit for postHBCR, 6-MW test. The mean 6-MW distance for these five patients before HBCR was 584 
feet (standard deviation 353.7) and postHBCR mean 6-MW distance was 620 feet (standard deviation 388.5).

\section{DISCUSSION}

According to the 2017 focused update of AHA guidelines, TAVR is recommended for both intermediate and high-risk surgical candidates with severe symptomatic aortic stenosis [1]. The American Association of Cardiovascular and Pulmonary Rehabilitation (AACVPR) recommends cardiac rehabilitation for patients with myocardial infarction, coronary artery bypass graft surgery $(\mathrm{CABG})$, percutaneous coronary intervention (PCI), chronic stable angina, peripheral arterial disease (PAD), and stable systolic heart failure patients [12]. However, no guidelines exist for cardiac rehabilitation, including home-based options, for post-TAVR patients despite various studies showing that it prolongs survival, reduces re-admission rates, and improves overall functional status in this patient population [1-4]. A more recent 2019 meta-analysis which included both sAVR and TAVR patients also reported a probable improvement in the exercise capacity of these patients after cardiac rehabilitation [6].

While the benefits of cardiac rehabilitation are well known, most programs are based either in a hospital or an outpatient center. As such, factors such as lack of transportation, time away from work, and access to rehabilitation programs present major barriers to participation in cardiac rehab [13]. To mitigate these barriers, physician-led, nurse-supervised home-based cardiac rehabilitation programs were started at several VAMCs throughout the country. Individualized exercise plans were created for the patients based on their capacity and goals and needed equipment was provided for use at home. Additionally, education about diet, smoking cessation, and stress management was also provided via weekly telephone calls. We studied the functional outcomes of 14 patients who completed HBCR at North Florida South Georgia VAMC in Gainesville, FL. Various performance measures mentioned in the Methods section were used for this assessment.

Per the latest statistics released by the U.S. Department of Veterans Affairs, women make up $10 \%$ of the veterans [14]. This is in close alignment with the percentage of women in our study population, $14 \%$ (two out of 14 patients). Given the subjectivity and personal onus involved in the completion of surveys, it is not entirely surprising that only half (14 out of 28 ) the veterans who finished the HBCR program filled out the surveys. Additionally, due to the remote nature of the program and the scattered locations of our patients across two states (as shown in Fig. 1), we did not require all participants to drive back to the clinic to complete the 6-MW test. As a result, only six of the 14 patients completed the post-HBCR 6-MW test while the remaining eight completed the rehab program via telephone. The mean 6-MW distance for these six patients before HBCR was 584 feet and the mean distance after HBCR was 620 feet. Due to limitation of sample size, Wilcoxon signed-rank comparison was not performed for the 6-MW test. As a result, only five of the 14 patients completed the post-HBCR 6-MW test while the remaining eight completed the rehab program via telephone. While the data was not analyzed for statistical difference due to a small sample size, the average distance walked by patients in the 6-MW test was greater after HBCR $(620 \pm 388.5$ feet post-HBCR vs. $584 \pm 353.7$ feet pre-HBCR).

Paired comparisons using the Wilcoxon signed-rank test for pre- and post-HBCR analysis revealed a trend towards significance for the DASI score ( $p$ value 0.05 ) while statistically significant improvement was seen in the DASIMets scores and SF-36 physical functioning scores ( $p$ values 0.034 and 0.016 , respectively). While the study population is limited, the consistency of subjective improvement in physical functioning across various instruments suggests that HBCR may play an important role in improving the physical well-being of patients after TAVR despite being an entirely homebased endeavor.

No significant difference was noted in the results of Life's Simple 7 survey and other domains of SF-36 instrument. There was a slight 
increase in bodily pain reported by patients from 51 to 57 but the difference can be attributed to the subjective variation in participants' answers over several weeks. Finally, the results of physical limitation due to physical health (RP) domain of SF-36 were invalid as only three patients completed this survey category prior to HBCR while six filled it out after HBCR. Therefore, the median was 0 , resulting in no statistically significant result.

Due to the scarcity of home-based cardiac rehabilitation (HBCR) programs in the country, the data on their efficacy are scant. While this pilot study is limited in its capacity to draw major conclusions due to a small population size, it does offer valuable insights into the role of HBCR in improving physical functioning in post-TAVR patients. Furthermore, it allowed patients across the two states of Florida and Georgia to participate in personalized cardiac rehabilitation regimens in their homes. Equipment was provided by the VA thereby eliminating travel to rehabilitation facilities.

The 2018 SPORT:TAVI randomized pilot study demonstrated that in the absence of continued exercise, the beneficial effects of cardiac rehabilitation are not sustained beyond the initial period [15]. While unexplored, the flexibility of time and location offered by HBCR may result in increased adherence and lasting long-term benefits among participants. This could be a future direction for investigation.

\section{CONCLUSIONS}

This pilot study gives significant insight into the role of HBCR in improving physical functioning of post-TAVR patients. However, due to a small sample size, the data from this study is more suggestive rather than conclusive. Further studies, specifically randomized multicenter control trials with direct comparisons of HBCR to existing rehabilitation options, are necessary to validate these data.

\section{ACKNOWLEDGEMENTS}

We thank the participants of this study.
Funding. This material is the result of work supported with resources and the use of facilities at the Malcom Randall Veterans Affairs Medical Center. Dr. David Winchester is supported by VA HSR\&D Career Development Award 13-023. This work does not represent the official views of the US government. No Rapid Service Fee was received by the journal for the publication of this article.

Authorship. All named authors meet the International Committee of Medical Journal Editors (ICMJE) criteria for authorship for this article, take responsibility for the integrity of the work as a whole, and have given their approval for this version to be published.

Authorship Contributions. This material is the result of work supported with resources and the use of facilities at the Malcom Randall Veterans Affairs Medical Center. Dr. David Winchester is supported by VA HSR\&D Career Development Award 13-023. No deserving authors have been omitted.

Disclosures. Gurjaspreet K. Bhattal, Ki E. Park, and David E. Winchester have nothing to disclose.

Compliance with Ethics Guidelines. In accordance with Veterans Affairs Handbook 1058.05, this quality improvement project was determined by the VA medical service chief to not qualify as human subjects research. As such, this project was not reviewed by our institutional review.

Data Availability. The datasets generated during and/or analyzed during the current study are available from the corresponding author on reasonable request.

Open Access. This article is licensed under a Creative Commons Attribution-NonCommercial 4.0 International License, which permits any non-commercial use, sharing, adaptation, distribution and reproduction in any medium or format, as long as you give appropriate credit to the original author(s) and the source, provide a link to the Creative Commons licence, and 
indicate if changes were made. The images or other third party material in this article are included in the article's Creative Commons licence, unless indicated otherwise in a credit line to the material. If material is not included in the article's Creative Commons licence and your intended use is not permitted by statutory regulation or exceeds the permitted use, you will need to obtain permission directly from the copyright holder. To view a copy of this licence, visit http://creativecommons.org/licenses/by$\mathrm{nc} / 4.0 /$.

\section{REFERENCES}

1. Nishimura RA, Otto CM, Bonow RO, et al. 2017 AHA/ACC focused update of the 2014 AHA/ACC guideline for the management of patients with valvular heart disease: a report of the American College of Cardiology/American Heart Association task force on clinical practice guidelines. Circulation. 2017;135(25):e1159-e1195195.

2. Ribeiro GS, Melo RD, Deresz LF, et al. Cardiac rehabilitation programme after transcatheter aortic valve implantation versus surgical aortic valve replacement: systematic review and meta-analysis. Euro J Preventive Cardiol. 2017;24(7):688-97 (PubMed PMID: 28071146. Epub 2017/01/11. Eng).

3. Voller H, Salzwedel A, Nitardy A, et al. Effect of cardiac rehabilitation on functional and emotional status in patients after transcatheter aortic-valve implantation. Euro J Preventive Cardiol. 2015;22(5):568-74 (PubMed PMID: 24577878. Epub 2014/03/01. eng.).

4. Russo N, Compostella L, Tarantini G, et al. Cardiac rehabilitation after transcatheter versus surgical prosthetic valve implantation for aortic stenosis in the elderly. Euro J Preventive Cardiol. 2014;21(11): 1341-8 (PubMed PMID: 23757283. Epub 2013/06/13. eng.).

5. Fauchere I, Weber D, Maier W, et al. Rehabilitation after TAVI compared to surgical aortic valve replacement. Int J Cardiol. 2014;173(3):564-6.

6. Anayo L, Rogers P, Long L, et al. Exercise-based cardiac rehabilitation for patients following open surgical aortic valve replacement and transcatheter aortic valve implant: a systematic review and metaanalysis. Open Heart. 2019;6:e000922. https://doi. org/10.1136/openhrt-2018-000922.

7. Bonnie Wakefield, Ph.D., R.N.; Kariann Drwal, M.S., Melody Scherubel1, et al. Rural Promising Practice Issue Brief: Remote, Telephone-Based Delivery of Cardiac Rehabilitation. U.S. Department of Veterans Affairs' Office of Rural Health. November 2016

8. Lloyd-Jones DM, Hong Y, Labarthe D, Mozaffarian D, Appel LJ, Van Horn L, Greenlund K, Daniels S, Nichol G, Tomaselli GF, Arnett DK, Fonarow GC, Ho PM, Lauer MS, Masoudi FA, Robertson RM, Roger V, Schwamm LH, Sorlie P, Yancy CW, Rosamond WD. Defining and setting national goals for cardiovascular health promotion and disease reduction: the American Heart Association's strategic impact goal through 2020 and beyond. Circulation. 2010;121:586-613.

9. Guyatt GH, Sullivan MJ, Thompson PJ, et al. The 6-minute walk: a new measure of exercise capacity in patients with chronic heart failure. Can Med Assoc J. 1985;132(8):919-23.

10. Hlatky MA, Boineau RE, Higginbotham MB, et al. A brief self-administered questionnaire to determine functional capacity (the Duke Activity Status Index). Am J Cardiol. 1989;64(10):651-4. https:// doi.org/10.1016/0002-9149(89)90496-7.

11. Ware JE Jr, Sherbourne CD. The MOS 36-item shortform health survey (SF-36). I. Conceptual framework and item selection. Med Care. 1992;30(6): 473-83.

12. [Internet]. Aacvpr.org. 2019 [cited 12 July 2019]. https://www.aacvpr.org/portals/0/resources/ professionals/crupdate2.06.12.pdf

13. Thomas RJ, Balady G, Banka G, et al. ACC/AHA clinical performance and quality measures for cardiac rehabilitation. A report of the American College of Cardiology/American Heart Association Task Force on Performance Measures. 2018;2018:24587.

14. Department of Veterans Affairs, Office of DGA, Veteran Population Projection Model (VetPop2016)

15. Pressler A, Förschner L, Hummel J, et al. Long-term effect of exercise training in patients after transcatheter aortic valve implantation: follow-up of the SPORT:TAVI randomized pilot study. Euro J Preventive Cardiol. 2018;25(8):794-801. 